\title{
Unresponsive hypertension in a child with meningoencephalitis due to paroxysmal sympathetic hyperactivity
}

\author{
*Panagoda Weththasinghage Prasad Chathurangana ${ }^{1}$, Jithangi Wanigasinghe ${ }^{2}$, D G Harendra de Silva ${ }^{3}$, S A \\ N Anuruddika Suraweera ${ }^{4}$, Vinushiya Gunalini Quienters ${ }^{5}$
}

Sri Lanka Journal of Child Health, 2017; 46(3): 284-287

DOI: http://dx.doi.org/10.4038/sljch.v46i3.8335

(Key Words: Paroxysmal sympathetic hyperactivity)

\begin{abstract}
Introduction
The clinical syndrome of paroxysmal sympathetic hyperactivity (PSH) is commonly identified in the intensive care setup in adults with traumatic brain injury having tachycardia, tachypnoea, hypertension, diaphoresis, fever and dystonia. This condition is not common in children and is usually described in neurointensive care units during management of acquired brain injury with constant blood pressure monitoring. In the absence of stringent blood pressure monitoring, PSH becomes difficult to recognize in a ward setting. However, diagnosis is crucial since the management of hypertension is different and features of hypertensive encephalopathy may not be identified separately. We describe a child managed in a general paediatric ward as for probable tuberculous meningitis complicated with PSH.
\end{abstract}

\section{Case report}

VV, an eight year old girl, was transferred due to continued fever for eleven days. She had been admitted to the local hospital with a five day history of fever, severe headache, vomiting and drowsiness. Her full blood count, C-reactive protein (CRP) and erythrocyte sedimentation rate (ESR) were within normal limits. She was started on IV cefotaxime and IV acyclovir.

\footnotetext{
${ }_{1}^{1}$ Senior Registrar, Professorial Paediatric Unit, Lady Ridgeway Hospital, Colombo, ${ }^{2}$ Consultant Paediatric Neurologist and Senior Lecturer in Paediatrics, Faculty of Medicine, University of Colombo, ${ }^{3}$ Professor of Paediatrics, Faculty of Medicine, University of Colombo, ${ }^{4}$ Registrar, ${ }^{5}$ House Officer, Professorial Paediatric Unit, Lady Ridgeway Hospital, Colombo.

*Correspondence: chathurangana@gmail.com (Received on 08 May 2016: Accepted after revision on 17 June 2016)

The authors declare that there are no conflicts of interest

Personal funding was used in formulating the article.

Open Access Article published under the Creative

Commons Attribution CC-BY (c) (i)
}

On admission to our unit, she was febrile, conscious and rational with a Glasgow coma scale of 15/15. She did not have either neck stiffness or positive Kernig sign. The neurological examination, including fundi, was normal. Her heart rate was $120 / \mathrm{min}$ and blood pressure was $112 / 74 \mathrm{~mm} \mathrm{Hg}\left(95^{\text {th }}\right.$ centile for height $118 / 78 \mathrm{~mm} \mathrm{Hg}$ ). There were no significant findings in the chest or abdomen. Features of sympathetic hyperactivity were not noted at that point.

Investigations revealed a white cell count of $14,200 / \mathrm{cu}$ $\mathrm{mm}(\mathrm{N} \mathrm{80 \%}$ ), haemoglobin ( $\mathrm{Hb})$ of $14 \mathrm{~g} / \mathrm{dl}$, platelet count of $242,000 / \mathrm{cu} \mathrm{mm}, \mathrm{CRP}<5 \mathrm{mg} / \mathrm{dl}$ and ESR $10 \mathrm{~mm} /$ hour. Renal functions and liver enzymes were within normal range (blood urea $3.7 \mathrm{mmol} / \mathrm{L}$, serum creatinine $57 \mu \mathrm{mol} / \mathrm{L}$, serum sodium $135 \mathrm{mmol} / \mathrm{L}$, serum potassium $4.3 \mathrm{mmol} / \mathrm{L}$, alanine transaminase 15 IU/L, aspartate transaminase $42 \mathrm{IU} / \mathrm{L}$ ). Computed tomography (CT) scan with contrast was normal. Cerebrospinal fluid (CSF) analysis on day 17 revealed 64 lymphocytes and 17 red cells. There were no polymorphs. Proteins were elevated $(68 \mathrm{mg} / \mathrm{dl})$ with a significant sugar difference (CSF sugar $2.9 \mathrm{mmol} / \mathrm{L}$ and blood sugar $7.1 \mathrm{mmol} / \mathrm{L}$ ). There were no organisms on direct smear and antigen tests for Streptococcus pneumoniae, Haemophilus influenzae, Neisseria meningitides and Cryptococcus were negative. Polymerase chain reaction (PCR) for tuberculosis (TB) and herpes simplex virus (HSV) and antibodies for Japanese encephalitis virus were negative. CSF culture did not grow any bacteria or fungi. Magnetic resonance imaging (MRI) of brain showed only slightly prominent lateral ventricles and extra-axial CSF spaces.

She developed features of sympathetic hyperactivity from day 13 onwards i.e. tachycardia (148 beats/min), tachypnoea (40/min), fine tremors of hands, anxiety and excessive sweating. Her blood pressure was $122 / 83 \mathrm{mmHg}$. These features were initially episodic and later became more constant. Nifedipine was started to control the blood pressure before PSH was considered. Two days later prazosin was added due to poor response. (Maximum 153/88 mm $\mathrm{Hg}$ ). 
Investigations for secondary causes of hypertension were negative with normal urine analysis, blood urea and creatinine. Ultrasound scan did not reveal any pathology of kidneys or any suprarenal masses. Doppler flow of both renal arteries were normal. Chest x-ray did not show a mediastinal mass and echocardiogram was normal. Thyroid stimulating hormone (TSH) was $1.69 \mathrm{mIU} / \mathrm{L}(0.7-4.6)$ and free thyroxine (T4) was $17.5 \mathrm{pmol} / \mathrm{L}$ (9-25). Urinary vanillylmandelic acid (VMA) level was $5.3 \mathrm{mg} / 24$ hours (1-11).

Apart from this complication, the patient's fever and headache were continuing. As the CSF report indicated bacterial meningitis and no clinical response was observed for 18 days with third generation cephalosporins, empirical treatment with anti TB medications combined with prednisolone was commenced. This was based on clinical suspicion although the ESR and CSF PCR testing for tuberculous bacillus were normal. The fever subsided gradually and completely resolved after 9 days of anti TB treatment (Day 27 of illness).

In the absence of a recognizable secondary cause for hypertension and lack of response to combined nifedipine and prazocin therapy, PSH was suspected and the patient was commenced on clonidine. Propranolol was not added due to the past history of asthma. Her blood pressure stabilized within 24 hours and nifedipine and prazocin were then withdrawn. All her symptoms and signs of sympathetic hyperactivity abated. Clonidine was continued for 7 days and tailed off over 2 weeks. The patient was discharged home on day 38 with anti-TB intensive phase treatment regime.

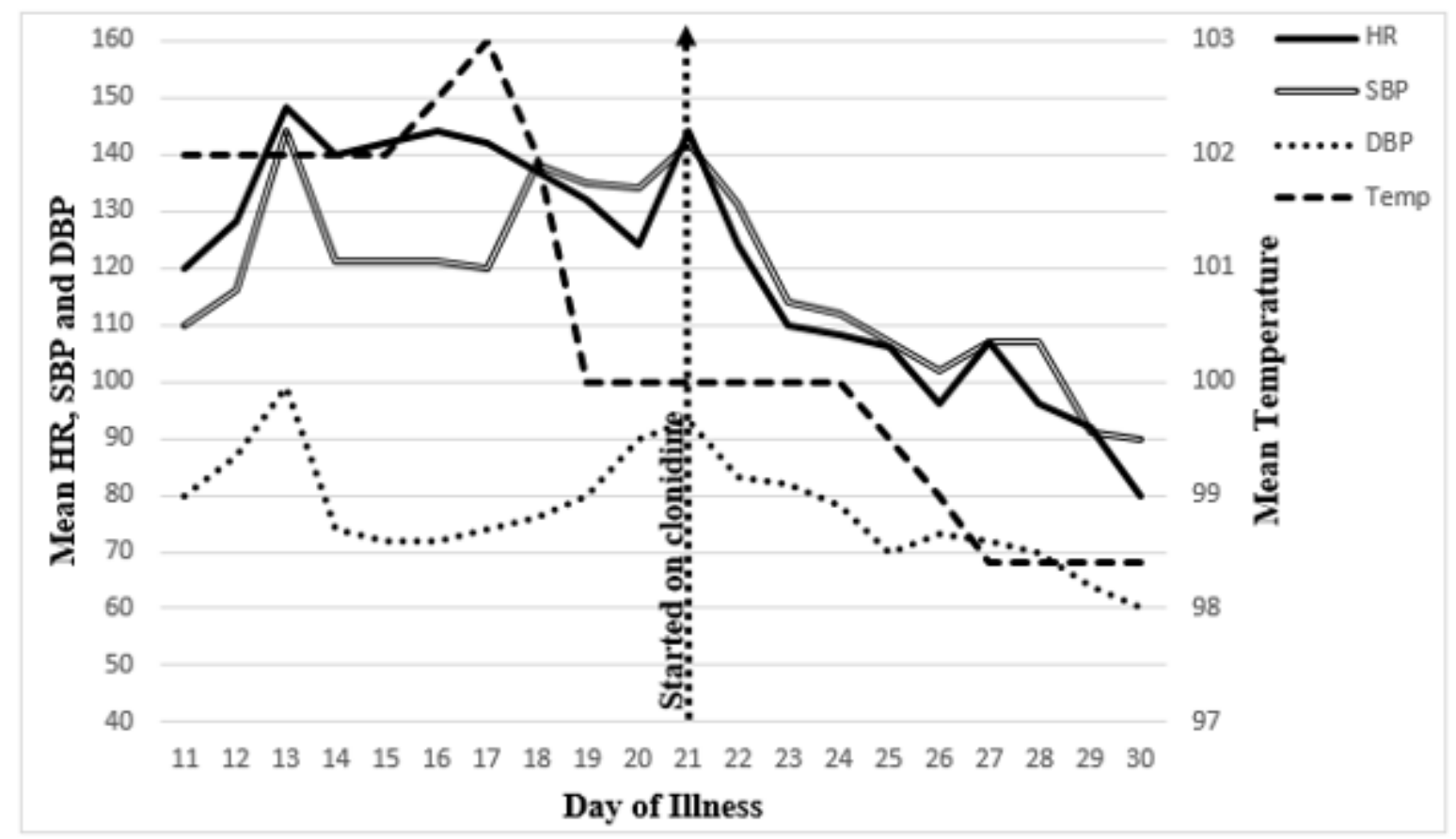

Figure 1: Mean heart rate (beats per minute), systolic blood pressure (in $\mathrm{mmHg}$ ), diastolic blood pressure (in $\mathrm{mmHg}^{\mathrm{H}}$ ) and temperature (in ${ }^{\circ} \mathrm{F}$ ) over 24 hours during the course of the illness. $H R=$ heart rate, $S B P=$ systolic blood pressure, $D B P=$ diastolic blood pressure, Temp $=$ Temperature

\section{Discussion}

Our patient had features of paroxysmal sympathetic hyperactivity (PSH) in the setting of a meningoencephalitis. Whether it was related to mycobacterial tuberculosis was not confirmed. PSH is a clinical disorder arising from the pathological hyperactivity of the sympathetic nervous system following acquired brain injury such as trauma, stroke, encephalitis and other types of brain injury. This disorder was first identified by Wilder Penfield in
1929, who labeled it as diencephalic autonomic epilepsy ${ }^{1}$. Since then, more than thirty names had been given to describe the same condition including autonomic seizures, brainstem attack, acute midbrain syndrome, autonomic storming and dysautonomia ${ }^{2}$. In 2007, the term "Paroxysmal Sympathetic Hyperactivity" was introduced ${ }^{3}$ and most experts consider it as the more clinically relevant term ${ }^{2}$. Despite its recognition for more than eight decades, this condition still lacks standardized clinical criteria 
and management guidelines ${ }^{4}$. Although brain injury is a leading cause of morbidity and mortality in children, there is limited data in the paediatric population ${ }^{5}$.

Incidence of PSH varies due to the lack of consensus on the diagnostic criteria ${ }^{4}$. The prevalence in children ranges from $6.4 \%$ to $13 \%$ following brain injury ${ }^{67}$. In one study, the underlying causes for PSH were traumatic brain injury (58\%), post cardiac arrest anoxic brain injury $(24 \%)$, infections $(9 \%)$ and brain neoplasms $(6 \%)^{6}$. PSH was three times more common following cardiac arrest than traumatic brain injury in children ${ }^{6}$.

Pathophysiology of PSH is poorly understood ${ }^{8}$. Although initially believed to be of epileptogenic origin, subsequent studies have failed to demonstrate any seizure activity in electroencephalograms ${ }^{2}$. Currently two theories are widely accepted. The first, known as the "Disconnection theory", states that injury to the inhibitory centres in the upper brainstem, diencephalon and cortex result in unopposed sympathetic outflow from downstream brainstem and spinal cord pathways ${ }^{4,9}$. The second, "ExcitatoryInhibitory model", proposes that injury to mesencephalon will reduce the descending inhibition, causing non-nociceptive stimuli to become nociceptive leading to allodynia. This in turn leads to an over-excitation of the sympathetic nervous system $^{4,10}$.

Main clinical manifestations of PSH are episodes of fever, tachypnoea, tachycardia, hypertension, diaphoresis and dystonia ${ }^{6}$. Some may have pupillary dilatation and intense flushing ${ }^{11}$. PSH usually appear 5-7 days after the injury but can start as early as 24 hours. Episodes occur on average 1 to 3 times per day and each episode can last from 1 to 10 hours. PSH may last between 1-2 weeks to several months ${ }^{11}$.

Different sets of diagnostic criteria for PSH have been proposed but none have gained universal acceptance ${ }^{2}$. It is a diagnosis of exclusion ${ }^{4}$. Widely accepted criteria are the presence of any four of the following features: fever, tachycardia, hypertension, tachypnoea, diaphoresis and dystonic posturing in the absence of other causative factors ${ }^{5,11}$.

PSH is a potentially treatable cause of increased secondary morbidity ${ }^{12,13}$. Although long term sequelae of PSH are not well established in adults, one study in children showed that it is associated with longer rehabilitation and worse functional outcome ${ }^{6}$. There is no consensus on the optimum management strategy of this potentially life threatening condition ${ }^{6}$, most evidence being limited to isolated case reports and small case series ${ }^{2}$. Most management protocols are directed towards amelioration of the overactive sympathetic autonomic system and reduction of the motor hyperactivity 2,6 . General principles of management of PSH include adequate hydration, effective analgesia, avoidance of triggers, providing a low-stimulation environment, treating hyperthermia and pharmacological agents, ${ }^{6,11}$. Pharmacological therapy for PSH involves 3 strategies ${ }^{4,11}$. These are 1) blocking end organ responses of the sympathetic nervous system e.g. propranolol, clonidine, 2) inhibiting afferent sensory processing to limit the development of allodynia e.g. gabapentin, baclofen and 3) reducing central sympathetic outflow e.g. clonidine, morphine, benzodiazepines, bromocriptine. Clonidine, an alpha 2 receptor agonist which is capable of reducing the central sympathetic outflow from hypothalamus and ventrolateral medulla, is most useful for treating the hypertension and tachycardia ${ }^{11}$. When hypertension occurs in a child with central nervous system involvement there are 2 possibilities viz. PSH or Cushing reflex ${ }^{14}$. However, Cushing reflex is associated with bradycardia in contrast to PSH which is associated with tachycardia.

This case report highlights the importance of actively looking for features of PSH when managing children with acute brain injury and using appropriate BP centile charts to diagnose hypertension. In PSH, clonidine is valuable in managing hypertension compared to standard antihypertensives which are ineffective.

\section{References}

1. Penfield W. Diencephalic autonomic epilepsy. Arch Neurol Psychiatry 1929; 22:358-74.

https://doi.org/10.1001/archneurpsyc. 19 29.02220020174010

2. Perkes I, Baguley IJ, Nott MT, Menon DK. A review of paroxysmal sympathetic hyperactivity after acquired brain injury. Annals of Neurology 2010; 68(2): $126-35$.

https://doi.org/10.1002/ana.22066

PMid: 20695005

3. Rabinstein AA. Paroxysmal sympathetic hyperactivity in the neurological intensive care unit. Neurological Research 2007; 29:680-2. https://doi.org/10.1179/016164107X240 071

PMid: 18173907 
4. Lump D, Moyer M. Paroxysmal sympathetic hyperactivity after severe brain injury. Current Neurology and Neuroscience Reports 2014; 14(11):494. https://doi.org/10.1007/s11910-0140494-0

PMid: 25220846

5. Farias-Moeller R, Carpenter JL, Dean N, Wells EM. Paroxysmal sympathetic hyperactivity in critically ill children with encephalitis and meningoencephalitis. Neurocritical Care 2015; 23(3):380-5. https://doi.org/10.1007/s12028-0150124-y

PMid: 25724178

6. Kirk KA, Shoykhet M, Jeong JH, et al. Dysautonomia after paediatric brain injury. Developmental Medicine and Child Neurology 2012; 54(8):759-64. https://doi.org/10.1111/j.14698749.2012.04322.x PMid: 22712762 PMCid: PMC3393822

7. Pozzi M, Conti V, Locatelli F, et al, Paroxysmal sympathetic hyperactivity in pediatric rehabilitation: clinical factors and acute pharmacological management. Journal of Head Trauma Rehabilitation 2015; 30(5):357-63.

https://doi.org/10.1097/HTR.000000000 0000084

PMid: 25310291

8. Baguley IJ, Heriseanu RE, Cameron ID, Nott MT, Slewa-Younan S. A critical review of the pathophysiology of dysautonomia following traumatic brain injury. Neurocritical Care 2008; 8: 293300.

https://doi.org/10.1007/s12028-007-

9021-3

PMid: 17968518
9. Blackman JA, Patrick PD, Buck ML, Rust RS Jr. Paroxysmal autonomic instability with dystonia after brain injury. Archives of Neurology 2004; 61(3): 321-8.

https://doi.org/10.1001/archneur.61.3.32 1

PMid: 15023807

10. Baguley IJ. Autonomic complications following central nervous system injury. Seminars in Neurology 2008; 28 (5):716-25.

https://doi.org/10.1055/s-0028-1105971 PMid: 19115177

11. Rabinstein AA, Benarroch EE. Treatment of paroxysmal sympathetic hyperactivity. Current Treatment Options in Neurology 2008; 10(2):1517.

https://doi.org/10.1007/s11940-0080016-y

12. Baguley IJ, Nicholls JL, Felmingham $\mathrm{KL}$, et al. Dysautonomia after traumatic brain injury: a forgotten syndrome? Journal of Neurology, Neurosurgery and Psychiatry 1999; 67:39-43.

https://doi.org/10.1136/jnnp.67.1.39

PMid: 10369820 PMCid: PMC1736437

13. Rabinstein AA. Paroxysmal autonomic instability after brain injury. Archives of Neurology 2004; 61: 1625

https://doi.org/10.1001/archneur.61.10.1

625-b

PMid: 15477525

14. Ayling, J. Managing head injuries. Emergency Medical Services 2002; 31 (8): 42.

PMid: 12224233 